\title{
Difficulties that Students Face when Learning Algebraic Problem-Solving
}

\author{
Chan Li Ying ${ }^{1}$, Sharifah Osman, ${ }^{2, *}$ Dian Kurniati ${ }^{3}$, Edi Sunjayanto Masykuri ${ }^{4}$, Jeya Amantha Kumar ${ }^{5}$, \\ Chuzairy Hanri ${ }^{2}$ \\ ${ }^{1}$ Austin Heights Private \& International Schools, Johor Bahru, Malaysia \\ ${ }^{2}$ School of Education, Faculty of Social Sciences and Humanities, Universiti Teknologi Malaysia, Johor Bahru, Malaysia \\ ${ }^{3}$ Department of Mathematics Education, Faculty of Teacher Training and Education, Universitas Jember, Indonesia \\ ${ }^{4}$ English Education Program, Universitas Muhammadiyah Purworejo, Indonesia \\ ${ }^{5}$ Centre for Instructional Technology and Multimedia, Universiti Sains Malaysia, Penang, Malaysia
}

Received July 22, 2020; Revised August 31, 2020; Accepted September 29, 2020

\section{Cite This Paper in the following Citation Styles}

(a): [1] Chan Li Ying, Sharifah Osman, Dian Kurniati, Edi Sunjayanto Masykuri, Jeya Amantha Kumar, Chuzairy Hanri , "Difficulties that Students Face when Learning Algebraic Problem-Solving," Universal Journal of Educational Research, Vol. 8, No. 11, pp. 5405 - 5413, 2020. DOI: 10.13189/ujer.2020.081143.

(b): Chan Li Ying, Sharifah Osman, Dian Kurniati, Edi Sunjayanto Masykuri, Jeya Amantha Kumar, Chuzairy Hanri (2020). Difficulties that Students Face when Learning Algebraic Problem-Solving. Universal Journal of Educational Research, 8(11), 5405 - 5413. DOI: 10.13189/ujer.2020.081143.

Copyright $@ 2020$ by authors, all rights reserved. Authors agree that this article remains permanently open access under the terms of the Creative Commons Attribution License 4.0 International License

\begin{abstract}
Algebraic problem-solving is a way of thinking and reasoning that allows students to create models, study relationships, and solve problems. However, students only have a little understanding of formulating and solving algebraic problems. This study aims to determine the predominant difficulties that Year Six students face when learning algebraic problem-solving. This study used a quantitative research design involving 80 students selected by purposive sampling. The instruments used in this study include criterion-referenced tests consisting of word and diagram algebraic problem-solving items. Data were analysed using GNU PSPP software. The descriptive statistics showed that the predominant difficulty that Year Six students faced when solving algebraic word problems was text difficulties and unfamiliar contexts. For diagrammatic algebraic problem-solving, students encountered the most difficulty with visual-spatial awareness. The Chi-Square test was used to identify the statistical correlation coefficient between gender and difficulties in solving algebraic problems. The result showed a positive association between gender and recognition difficulties and gender and sign substitution error. The findings of this study may encourage students to better learn algebraic problem-solving skills. Moreover, this study also provides important information for teachers to better teach algebraic problem-solving to Year Six
\end{abstract}

students. Keywords Problem-Solving, Chi-Square Test,
Algebraic Problems

\section{Introduction}

Mathematical skills and knowledge must be mastered because they form the basis of daily life, career development, and science and technology [1]. Mathematics is not reasoning but rather imagination; students are required to have a creative imagination to explore mathematical issues. Some researchers have mentioned that, for talented math students, the early mastery of concepts and skills in mathematics courses often lead to more of the same work and faster adoption of the course [2-3]. Furthermore, students can learn mathematics effectively through specializing, generalizing, conjecturing, and convincing activities [4]. Through these activities, they can understand the direct mathematical object such as mathematical facts, concepts, principles, and procedures in-depth, and even solve mathematical problems better [5].

Algebra is a topic that must be studied by every student from elementary school to university. However, in the 
future, algebra is also important for employment opportunities [6-7]. Algebra is one of the major topics that require students to adopt logical thinking, which, in turn, challenges the students' skills and allows them to focus on arithmetic operations while focusing on the use of symbols to represent equations and to establish the relationships in mathematical operations [8]. Problem-solving performance can be determined based on five broad independent factors, namely knowledge acquisition, and utilisation, control, beliefs, as well as social and cultural contexts [9]. Problem-solving skills become important when applying mathematics in different situations. Students need to integrate the skills and concepts of problem-solving to solve specific mathematical situations [10].

The difficulties faced by students are more obvious when solving a problem that requires them to transmit a mathematical sentence into a mathematical operation [1]. Meanwhile, researchers highlight the same difficulties such as translating words to algebra or vice versa, misinterpreting the meaning of algebraic expressions, misunderstanding and incorrectly substituting signs, and using wrong algebraic concepts to solve common mathematics problems [11]. According to [7], the main difficulties experienced by students in completing word problems related to algebra are turning problems into mathematical symbolic problems and formulating equations, schemes, or diagrams. [12] pointed out other difficulties such as text difficulties, unfamiliar contexts, using inappropriate strategies, and a lack of solving skills. Students are unable to score well in mathematics examination because they have a lack of algebraic skills that are required for other mathematics subtopics. Students are required to have algebraic problem-solving skills when learning and solving algebraic questions so they can better construct algebraic equations to come up with the correct solution [13].

Therefore, actions must be taken to recognise the difficulties that both students and teachers face in learning and teaching mathematics. If the teacher knows the difficulties experienced by students in learning mathematics, especially algebra, then the teacher can determine a solution by designing algebraic learning that minimizes the difficulties experienced by students. [14] identified the students' difficulties in learning mathematics revolved around conceptual processing, language, visual-spatial processing, organisation, memory, attention, and psychosocial problems. Furthermore, conceptual errors that are always experienced by elementary school students are errors using symbols, general algebraic concepts, the abstract nature of algebra, and precision [15-16]. Meanwhile, researchers found that students had difficulties translating a word to algebra or vice versa. Students who rely on memorising rules will misuse or misapply mathematical expressions, especially in algebra. This case leads to problems in learning algebra, as the students fail to solve either word-based or diagram-based algebraic questions [17].
Sometimes, young students fail to understand expression in a question that contains more than one operation, so they fail to understand the meaning of the equal sign, which is the inverse of the relationship between addition and subtraction or multiplication and division [1]. Students are also unable to describe strategies or explain their reasoning for algebraic problem-solving. Also, they cannot justify solutions, or make persuasive arguments, thus rendering them unable to solve questions. Students face difficulties in reading directions and problems (a comprehension challenge) and face difficulties in writing explanations or the proper mathematical thinking, as this requires some time for them to get started on writing the solution for the algebraic problem [14]. Making connections, mathematical sentences, and understanding graphical representations are the key difficulties that students face when solving problems because they cannot organise the information given to them [18]. Text difficulties and unfamiliar contexts, recognition difficulties, visual-spatial skills, sign substitution errors, language, and translation of words or diagrams to algebra are therefore the main focus of this study because most students face difficulties in these six areas.

Several studies have discussed the relationship between gender and the ability or difficulty in solving algebra problems. The results of the study stated that gender differences were not significantly related to conceptual difficulties in solving algebra problems [19-21]. But there are other studies that state that gender differences are linearly correlated with differences in the difficulties they experience in solving algebra problems, especially those related to numeracy, equality, and number patterns [22-24]. Referring to the results of the study, there are differences in the results of research related to gender relations with algebraic problem solving conducted by students from elementary school to college. Therefore, a statistical test is needed to determine the correlation between gender differences and the difficulties experienced in solving algebra problems.

Based on the above discussion, this research aims to determine the difficulties that primary Year Six students face when learning to solve algebraic word problems and diagrammatic problems. The research objectives are, therefore:

i To determine the predominant difficulties that Primary Six students face in learning algebraic problem-solving.

ii To determine the predominant difficulties that Primary Six students face in learning algebraic word problems and diagram problems.

iii To identify whether or not there is a statistical correlation coefficient between gender and difficulties in algebraic problem-solving.

This study aims to answer the following hypotheses:

$\mathrm{H}_{0}$ : Gender and difficulties in algebraic problem-solving are independent.

$\mathrm{H}_{1}$ : Gender and difficulties in algebraic problem-solving 
are not independent.

\section{Materials and Methods}

In this research, quantitative data was collected from a criterion-referenced test. A descriptive case study research design was also adopted. Quantitative data were used to analyse the overall difficulty level that Year 6 students faced in solving algebraic questions. In this research, quantitative data from three classes in Year 6 were analysed descriptively using percentages. A criterion-referenced test was designed to determine the difficulties that the students experienced and the mistakes they committed during tests. In the process of evaluation, the difficulties of the students were classified according to type. Past researchers have mentioned that the best approach, in this case, is to plan the procedure for all the research steps-from data collection, analysis, to the result interpretations - to yield in-depth information of the research objective (in this case, the difficulties students face in algebraic problem-solving) [25].

The targeted participants of this study were students from three Year 6 classes studying in a private international school, Johor. The students were 10 to 12 years old. Eighty students were from Class A $(n=27), 24$ students were from Class B $(n=24)$, and 29 students were from Class C $(n=29)$. All the participants had some background knowledge of Algebra. The populations targeted in this study were Year 6 Primary School students because they are about to advance to Secondary level in Year 7.

This study adopted the survey instrument as per past quantitative research studies. A criterion-referenced test was also employed. The criterion-referenced test measures student performance against a criterion that matches the intended learning outcomes. The Criterion-Referenced Assessment assesses the specified level of performance following a rubric of student understanding and difficulties in solving algebraic problems. The marks given were based on the criterion-referenced measures rubric [26]. The questions in the test were set to past Year 6 CheckPoint tests from 2015-2018, with modifications. The questions in the test consisted of 10 items that were based on the concepts and knowledge the students had learned in class. Five items were algebraic word problems and another 5 items were algebraic diagram problems. Each item was worth 2 marks. Zero marks would be given if the students did not answer or if they provided the wrong answer; 1 mark would be given if they were able to prove their solution but provided an incorrect answer, and the full 2 marks would be given if they were able to answer the question correctly. The correct answer would obtain 2 marks. The total marks that could be obtained were 20. This step tests the students' concepts and the required knowledge that they have to solve algebraic problems. The students were required to complete the test individually, within 40 minutes, without any discussion. The students' difficulties when solving algebraic questions were identified via the test given. The instrument used to identify the students' difficulties in learning algebraic problem-solving was the 20-mark test consisting of 10 items. This test was verified by the Head of the Secondary Mathematics Department at the private international school. The Head has had more than 40 years of experience and was a senior lecturer of mathematics in one of the research universities in Malaysia. Ten algebra problems used in this study were presented in table 1 .

Table 1. The Algebra Problems

\begin{tabular}{cc}
\hline Number & Problems \\
\hline 1 & Language Understanding \\
\hline 2 & Information Skill: Manipulating Procedure \\
\hline 3 & Language Skill: Number Value \\
\hline 4 & Text difficulties \& Unfamiliar contexts \\
\hline 5 & Arithmetic Skill - Procedural Knowledge \\
\hline 6 & Information Skill - Manipulating Information \\
\hline 7 & Information Skill - Understand the Objective \\
\hline 8 & Visual-Spatial Skill - Application to Daily Life \\
\hline 9 & Visual-Spatial Skill - Orientation of Shape \\
\hline 10 & Visual-Spatial Skill - Application to Daily Life \\
\hline
\end{tabular}

\section{Results}

Table 2 shows the descriptive statistics of all variables. Item 8 had the highest standard deviation of 0.95 out of the 10 items representing algebraic problem-solving questions. Item 1 to Item 5 tested the students' difficulties in solving word problems whereas Item 6 to Item 10 tested the students' difficulties in solving diagrammatic problems. From Table 2, the results show that Item 1 had the highest standard deviation of 0.93 of all the word problems whereas Item 8 had the highest standard deviation of 0.95 of all the diagrammatic problems.

Table 2. The descriptive statistics of all variables $(\mathrm{N}=80)$

\begin{tabular}{ccccc}
\hline Item & Min & Max & Mean & $\begin{array}{c}\text { Standard } \\
\text { Deviation }\end{array}$ \\
\hline $\begin{array}{c}\text { Word } \\
\text { Problem }\end{array}$ & & & & \\
\hline Item 1 & 0 & 2 & 0.63 & 0.93 \\
\hline Item 2 & 0 & 2 & 1.63 & 0.79 \\
\hline Item 3 & 0 & 2 & 0.35 & 0.76 \\
\hline Item 4 & 0 & 2 & 0.15 & 0.53 \\
\hline Item 5 & 0 & 2 & 0.28 & 0.69 \\
\hline Diagram & & & & \\
Problem & & & & \\
\hline Item 6 & 0 & 2 & 0.38 & 0.79 \\
\hline Item 7 & 0 & 2 & 0.38 & 0.79 \\
\hline Item 8 & 0 & 2 & 0.68 & 0.95 \\
\hline Item 9 & 0 & 2 & 0.50 & 0.87 \\
\hline Item 10 & 0 & 2 & 0.13 & 0.49 \\
\hline
\end{tabular}


As stated in Table 3, the students' difficulties in solving algebraic problems can be classified into text difficulties, recognition difficulties, visual-spatial skill, sign substitution error, as well as language and translation of words or diagrams to algebra. Each item can be categorised into several types of algebraic problem-solving difficulties.

Table 3. Difficulties of each item

\begin{tabular}{|c|c|c|c|}
\hline Question & Difficulty & $\begin{array}{c}\text { Wrong } \\
\text { Answer }\end{array}$ & $\begin{array}{l}\text { Correct } \\
\text { Answer } \\
\end{array}$ \\
\hline Item 1 & $\begin{array}{c}\text { Language } \\
\text { Understanding }\end{array}$ & 55 (68.74\%) & 25 (31.25\%) \\
\hline Item 2 & $\begin{array}{l}\text { Information Skill: } \\
\text { Manipulating } \\
\text { Procedure } \\
\end{array}$ & 15 (18.75\%) & 65 (81.25\%) \\
\hline Item 3 & $\begin{array}{l}\text { Language Skill: } \\
\text { Number Value }\end{array}$ & 66 (82.50\%) & $14(17.50 \%)$ \\
\hline Item 4 & $\begin{array}{l}\text { Text Difficulties } \\
\text { \&Unfamiliar } \\
\text { contexts } \\
\end{array}$ & 74 (92.50\%) & $6(7.50 \%)$ \\
\hline Item 5 & $\begin{array}{c}\text { Arithmetic Skill } \\
\text { - Procedural } \\
\text { Knowledge } \\
\end{array}$ & 69 (86.25\%) & 11 (13.75\%) \\
\hline Item 6 & $\begin{array}{c}\text { Information Skill - } \\
\text { Manipulating } \\
\text { Information } \\
\end{array}$ & 65 (81.25\%) & 15 (18.75\%) \\
\hline Item 7 & $\begin{array}{c}\text { Information Skill } \\
\text { - Understand the } \\
\text { Objective }\end{array}$ & 65 (81.25\%) & 15 (18.75\%) \\
\hline Item 8 & $\begin{array}{l}\text { Visual-Spatial Skill } \\
\text { - Application to } \\
\text { Daily Life }\end{array}$ & 53 (66.25\%) & 27 (33.75\%) \\
\hline Item 9 & $\begin{array}{c}\text { Visual-Spatial Skill } \\
\text { - Orientation of } \\
\text { Shape } \\
\end{array}$ & 60 (75\%) & 20 (25\%) \\
\hline Item 10 & $\begin{array}{l}\text { Visual-Spatial Skill } \\
\text { - Application to } \\
\text { Daily Life }\end{array}$ & 72 (90\%) & 8 (10\%) \\
\hline
\end{tabular}

As shown in Table 4, the items under the algebraic problem-solving categories are based on different difficulties. The questions were based on past year Mathematics Check Point papers from the year 20152018.

Table 4. Students' Difficulties in Algebraic Problem-Solving

\begin{tabular}{c}
\hline Difficulty \\
Visual-spatial skill \\
Item 7, Item 8, Item 9, Item 10 \\
\hline Text difficulties and Unfamiliar contexts \\
Item 4 \\
Language \\
Item 1, Item 3 \\
\hline Recognition Difficulties \\
Item 6 \\
\hline Sign Substitution Error \\
Item 5 \\
\hline Translation of words or diagrams to algebra and vice versa \\
Item $\mathbf{2}$
\end{tabular}

Table 5 shows the statistical frequency of difficulties among male and female students. Specifically, it shows that more female students had visual-spatial skill difficulties, text difficulties, and unfamiliar contexts, recognition difficulties, and sign substitution error difficulties when compared to male students when it came to algebraic problem-solving. However, the male students faced more language difficulties and difficulties in translating words or diagrams to algebra and vice versa in comparison to female students.

Table 5. The statistical frequency of difficulties among male and female students

\begin{tabular}{|c|c|c|}
\hline \multirow[b]{2}{*}{ Gender/Difficulty } & Male & Female \\
\hline & $\begin{array}{c}\text { Frequency/Percentage } \\
(\%)\end{array}$ & $\begin{array}{c}\text { Frequency/Percentage } \\
(\%)\end{array}$ \\
\hline \multirow{4}{*}{ Visual-spatial skill } & $28(35 \%)$ & $37(46.25 \%)$ \\
\hline & $25(31.25 \%)$ & $28(35.00 \%)$ \\
\hline & $29(36.25 \%)$ & $31(38.75 \%)$ \\
\hline & $36(45 \%)$ & $39(48.75 \%)$ \\
\hline $\begin{array}{l}\text { Text difficulties } \\
\text { and unfamiliar } \\
\text { contexts }\end{array}$ & 36 (45\%) & 38 (47.50\%) \\
\hline Language & $\begin{array}{c}28(35 \%) \\
34(42.50 \%)\end{array}$ & $\begin{array}{c}27(33.75 \%) \\
32(40 \%)\end{array}$ \\
\hline $\begin{array}{c}\text { Recognition } \\
\text { difficulties }\end{array}$ & $28(35.00 \%)$ & 37 (46.25\%) \\
\hline $\begin{array}{c}\text { Sign substitution } \\
\text { error }\end{array}$ & 31 (38.75\%) & 38 (47.50\%) \\
\hline $\begin{array}{l}\text { Translation from } \\
\text { word or diagram to } \\
\text { algebra and vice } \\
\text { versa }\end{array}$ & $8(10 \%)$ & 7 (8.75\%) \\
\hline
\end{tabular}

The results of Pearson's Chi-Square Test are shown in Table 6. The result also shows the p-value of each item to be matched with its difficulty in Table 5 .

Table 6. The results of Pearson's Chi-Square of Association

\begin{tabular}{ccc}
\hline & Pearson's Chi-Square & P-value \\
\hline Item 1 & 0.06 & 0.809 \\
\hline Item 2 & 0.08 & 0.775 \\
\hline Item 3 & 0.35 & 0.556 \\
\hline Item 4 & 0.72 & 0.396 \\
\hline Item 5 & 5.16 & 0.023 \\
\hline Item 6 & 6.65 & 0.010 \\
\hline Item 7 & 6.65 & 0.010 \\
\hline Item 8 & 0.50 & 0.478 \\
\hline Item 9 & 0.27 & 0.606 \\
\hline Item 10 & 1.92 & 0.166
\end{tabular}

Referring to the results shown in Table 7, Chi-Square shows a statistical result of $X^{\wedge} 2(9.16, N=80)=0.057$, so there is no significant relationship between gender and visual-spatial skill difficulty. In other words, visual-spatial difficulties in algebraic problem-solving were not affected by gender differences. Moreover, the relationship between the two variables is weak. As shown in Table 5, 36 male students and 39 female students out of a total of 80 students faced visual-spatial difficulties when answering Item 10. 
For the text difficulties and unfamiliar context, the results showed $X^{\wedge} 2(0.72, N=80)=0.396$, so there is no significant relationship between gender and text difficulties. Likewise, both male and female students did not face many text difficulties or unfamiliar contexts in algebraic problem-solving. That is, 36 male Year 6 students and 38 female Year 6 students had difficulties with the text but the relationship between gender and text difficulties was weak.

Table 7. The results of Pearson's Chi-Square of Association between Gender and Algebraic Problem-Solving Difficulties

\begin{tabular}{ccc}
\hline Gender/Difficulty & $\begin{array}{c}\text { Pearson's } \\
\text { Chi-Square }\end{array}$ & P-value \\
\hline $\begin{array}{c}\text { Visual-spatial skill } \\
\text { Text difficulties and unfamiliar } \\
\text { contexts }\end{array}$ & 9.16 & 0.057 \\
\hline Language & 0.72 & 0.396 \\
\hline Recognition Difficulties & 3.02 & 0.388 \\
\hline Sign substitution error & 6.65 & 0.010 \\
\hline $\begin{array}{c}\text { Translation of word or diagram to } \\
\text { algebra and vice versa }\end{array}$ & 5.16 & 0.023 \\
\hline
\end{tabular}

$\mathrm{H}_{0}$ : Gender and difficulties in algebraic problem-solving are independent

$\mathrm{H}_{1}$ : Gender and difficulties in algebraic problem-solving are not independent

Besides that, Table 7 shows the result of $\mathrm{X}^{\wedge} 2(3.02, \mathrm{~N}=$ $80)=0.388$ for language skills, indicating that there is no significant relationship between gender and language difficulties. That is, 34 male students and 32 female students in Year 6 experienced language difficulties but gender difference does not affect language skills or text difficulties and unfamiliar context skills, as shown by Item 4.

However, there is a significant relationship between gender and recognition difficulties, where $\mathrm{X}^{\wedge} 2(6.65, \mathrm{~N}=$ $80)=0.010$ and gender and sign substitution error, where $\mathrm{X}^{\wedge} 2(5.16, \mathrm{~N}=80)=0.023$. As shown in Table 5, male students experienced fewer recognition difficulties than female students when solving algebraic problems. Likewise, sign substitution errors occurred less frequently among male students as compared to female students. Male students also faced less difficulty in recognising algebraic problems compared to female students. This result proves that male and female students both had recognition difficulties and committed sign substitution errors.

Based on Table 7, there is no significant relationship between gender and difficulties in translating a word or a diagram to algebra and vice versa, as justified by the result of $X^{\wedge} 2(0.08, N=80)=0.775$. Only 8 male students and 7 female Year 6 students faced this problem. This result proves that algebraic problem-solving is not affected by gender.

\section{Discussion}

\section{Predominant Difficulties in Learning Algebraic Problem-Solving among Primary Six Students}

From the results above, most of the students (92.50\%) faced text difficulties and unfamiliar contexts. Students need to master language skills to adopt new knowledge. Students need to master basic skills so they can transmit mathematical sentences into solutions [27]. Previous researchers have proven that mastering language skills are more important now more than ever, as students need to have high-level reading skills to translate and summarise questions given to them [28]. [29] mentioned that language skills are important, as students are required to express their solutions in the language of mathematics. This case is especially true for algebraic word problems that call for more complicated reasoning to deal with unknown numbers.

From the result of the analysis of this study, the predominant difficulty that Year 6 students faced was text difficulties. The students were confused with the sentence in the question and were unable to identify or create a linear strategy. For example, "Three more than four times" should be translated to $4 x+3$ but the students misunderstood the questions and identified the solution as $3 \times 4$ instead. [30] proved that the symbolic language of algebra is not common because it is not the simple symbolic arithmetic language that students have experienced in the past. This is also following the opinion of [7] which states that the main difficulty experienced by students in solving algebraic problems is turning problems into mathematical models (sentences or texts into mathematical models) which are often referred to as horizontal mathematical.

Furthermore, the results above prove that the second-most prevalent difficulty among students when solving algebraic problems was a lack of visual-spatial skills, where $90 \%$ of the students were unable to answer the visual-spatial problem related to daily life applications. As highlighted in past research, the difficulties that students face in algebraic problem-solving could influence their performance. Some researchers have identified the difficulties that students faced in solving questions [8]. [31] found that algebraic problem-solving difficulties that school students faced include solving unknown equations and describing and using functions. [32] reported that understanding and using algebraic methods was one of the major problems students faced when learning algebra.

Previously, researchers have found that the biggest difficulty that students faced was the inability to conceptually process the problem at hand, in which one of the tasks was to understand the letter or symbolic form of the algebraic equations presented to them [14]. Similarly, a majority of students struggle to learn and understand mathematical concepts. They find it difficult to link 
certain theories to the mathematical problem and to the idea of solving the problem [33]. Past researchers have proven that visual-spatial skill was a major problem that students faced when solving diagrammatic algebraic problems [27]. This finding is consistent with that of [1] who conducted a test on Year 6 students to gauge their algebraic problem-solving skills. The study found that the students obtained the lowest score for visual-spatial skill questions. Not only that, but previous researchers have also found that students felt it was difficult to transform diagrammatic problems into real pictures, as they found it challenging to understand, so they would use the wrong algebraic method to solve the problem at hand [32]. Apart from the above problems, it is also important to look into the students' focus on conceptual understanding, which is a precursor to algebraic thinking. The process of developing algebraic visual-spatial skills among primary school students does not depend on 'chalk and talk' but rather requires research into many external factors that must be immediately implemented to solve this problem.

In previous studies, researchers claim that students face calculation problems, but these problems are not related to reading ability or general cognitive ability, unlike word problems, which are related to the reading skills [34]. Based on the current study, $82.50 \%$ of the Year 6 students from the International School investigated in this study faced language difficulties. These students are exposed to English as the main medium of learning and communication. [34-35] found that students felt it was difficult to write explanations of their mathematical thinking because they did not know how to express their ideas into mathematical language similar to the findings of the current study. Students were found weak at expressing their solutions into mathematical language and symbols and were unable to get the correct answer. [34] claimed that students have difficulties reading the questions given and therefore misunderstand the hints and direction to solve the problem. Based on Item 1, the students misunderstood certain mathematical language such as "less than" and "more than", resulting in their misunderstanding of the directions for solving the questions given.

\section{Predominant Difficulties that Primary Six Students Face when Solving Algebraic Word and Diagram Problems}

Based on the data analysis above, it can be concluded that text and context difficulties are the major difficulties that Year 6 students face when solving algebraic word problems. [34] mentioned that students faced problems when they were unable to translate words into number sentences. Besides that, students also faced problems in solving calculation problems. However, this case is unrelated to the students' reading ability or general cognitive ability. On the other hand, the word problems that students faced are related to reading skills. The students in this study were unable to find the missing unknown that was required by the questions. They also misunderstood the meaning of the question such that they used the wrong strategy to determine the answer. Researchers claim that students do not understand the difference between a letter that is a specific unknown and a letter that is used to generalise a number.

Moreover, students lack the skill to perform factorisations or to generate different parts of questions, including the equivalent sign, due to an inadequate perception of the algebraic structure [36]. Based on the results above, the predominant difficulties that students face when solving diagrammatic algebraic problems was their application in daily life. Reasoning skills for daily life is important for students to increase their performance in solving algebraic problems. According to [37], students acquire mathematical knowledge, problem-solving skills, and decision-making skills to cope with daily life challenges. To master logical reasoning and mathematics, teachers need to explicitly apply teaching strategies that enable their students to understand the relationship between strategies and concepts when problem-solving [1].

\section{The Statistical Correlation Coefficient Between Gender and Difficulties in Algebraic Problem-Solving}

This study identified the difficulties that students faced when solving algebraic problems, namely (1) visual-spatial skill, (2) text difficulties and unfamiliar context, (3) language skill, (4) recognition difficulties, (5) sign substitution error, and (6) translation of words or diagrams to algebra and vice versa.

The results showed a positive association (a path coefficient of 0.057) between gender and visual-spatial difficulties among the Year 6 students. Also, the Chi-Square test returned a value of 9.16. Therefore, gender and visual-spatial difficulties are independent. In other words, male and female students probably do not have different visual-spatial skill difficulties, as shown in Table 7. Male students develop their understanding of a question given by thinking differently, by solving the solutions given, and by checking the answer that was written again [6].

Besides that, there is an independent relationship between text difficulties and unfamiliar contexts and gender. A positive association (a path coefficient of 0.396) was recorded between gender and algebraic problem-solving. Hence, gender does not significantly affect the text difficulties that Year 6 students face when learning to solve algebraic problems. The analysis of text difficulties with missing information before the equal sign should, therefore, provide greater insight into the effect of equal-sign instruction for word problems. The attitude of female students such as anxiety and a lack of confidence will cause them to perform poorly [38-39].

Moreover, the language used in algebraic 
problem-solving is positively associated (a path coefficient value of 0.388 ) with gender, as it has a significant effect on Year 6 students' algebraic problem-solving. The result shows an independent relationship between gender and language difficulties among Year 6 learning algebraic problem-solving. Past researchers have mentioned that male students are more capable of interpreting mathematics language compared to female students because the former have a higher reasoning ability compared to the latter [6]. This is also consistent with the results of [24] study which stated that female students were defeated by their male counterparts in numerical assessments at all levels and this difference was statistically significant.

There is a positive association (a path coefficient of 0.775 ) between gender and difficulties in translating words or diagrams to algebra and vice versa among Year 6 students, with a Chi-Square value of 0.18 . Therefore, researchers believe that both variables are independent. That is, gender did not cause a difference in difficulties to translate a word or diagram to algebra and vice versa. That is because male or female students have the same difficulty in horizontal or vertical mathematical processes when solving algebra problems [7].

However, Table 7 shows a negative association (a path coefficient of 0.010) between gender and recognition difficulties. Besides, there was also a negative association (a path coefficient of 0.023) between gender and sign substitution error. From the results obtained, the male students' performance was better than the female students' when solving algebraic problems. According to [40], although girls are more independent in mathematics activities and will treat the tasks given seriously, boys can complete the tasks better but tend to be more careless than the girls. They would not read and follow the instructions given and they have their way of answering the questions using their terms. Students lack sufficient practice at home, as they tend not to manage extra time, causing them to be weak at mathematics.

The researchers believe that gender difference is an important factor, as male and female students perform differently depending on their learning preferences. The researchers believe that the difference between genders is caused by the influence of sex hormones, study style, cognitive skills, and attitude, all of which contribute to their mathematical problem-solving skills, but only to a certain extent and on certain mathematical fields.

Overall, this study highlighted the factors affecting Year 6 student performance in solving algebraic problems. The main objective of the present study was to determine the predominant algebraic problem-solving difficulties that Year 6 students faced. Additionally, this study found that the students faced predominant difficulties when solving both word and diagram-based algebraic problems. Lastly, this study found statistical relationships between gender and algebraic problem-solving difficulties.

\section{Conclusion}

For future research, there are some aspects to be taken into consideration for further improvement of the study as recommended below.

This study only involved year 6 students and was limited to the mathematics topic of algebra. In the future study, researchers could look into different mathematics topics or different subjects to find out the predominant difficulties in problem-solving. The researchers can also extend the research area by not limiting the sample to private school students. The study can be carried out using different research approaches such as a qualitative case study research design to have a deeper understanding of the difficulties in algebraic problem-solving from both teacher's and student's perspectives and multiple data sources.

This study has focused on the students' metacognitive and conceptual understanding of algebraic problems, therefore future research can broaden the scope by applying higher-order thinking questions and the implementation of $21^{\text {st }}$-century teaching methods for having better insights into the context of the study. Besides gender, other aspects can also be investigated such as by years of study, family background, and level of students' critical thinking and metacognitive skills.

\section{Acknowledgements}

This work was supported by the Research University Grant (Q.J130000.2553.20H86).

\section{REFERENCES}

[1] Tambychik, T., Meerah, T. S. M., \& Aziz, Z. (2010). Mathematics skills difficulties: A mixture of intricacies. Procedia - Social and Behavioral Sciences, 7(C), 171-180. https://doi.org/10.1016/j.sbspro.2010.10.025.

[2] Ling, C. Y., Osman, S., Daud, M. F., \& Hussin, W. N. W. (2019). Application of Vee Diagram as a Problem-Solving Strategy in Developing Students ' Conceptual and Procedural Knowledge. International Journal of Innovative Technology and Exploring Engineering (IJITEE), 8(10), 2796-2800 doi:10.35940/ijitee.J9591.0881019

[3] Fishman, T.D., Ludgate, A., \& Tutak, J. (2017). Success by design.

https://www2.deloitte.com/us/en/insights/industry/public-se ctor/improving-student-success-in-higher-education.html

[4] Stacey, K. (2006). What Is Mathematical Thinking and Why Is It Important? Progress Report of the APEC Project: Collaborative Studies on Innovations for Teaching and Learning Mathematics in Different Cultures (II) - Lesson Study Focusing on Mathematical Thinking. Retrieved from Http://E-Archives.Criced.Tsukuba.Ac.Jp/Data/Doc/Pdf/2. https://doi.org/10.3102/0034654312457429 
[5] As'ari, A. R., Kurniati, D., \& Subanji. (2019). Teachers Expectation of Students' Thinking Processes in Written Works: A Survey of Teachers' Readiness in Making Thinking Visible. Journal on Mathematics Education, 10(3), 409-424.

[6] Kusumaningsih, W., Darhim, Herman, T., \& Turmudi. (2018). Gender differences in algebraic thinking ability to solve mathematics problems. IOP Conf. Series: Journal of $\begin{array}{llll}\text { Physics: } \quad \text { Conf. Series } 1013 & \text { (2018) } 012143\end{array}$ doi :10.1088/1742-6596/1013/1/012143.

[7] Jupri, A., \& Drijvers, P. (2016). Student Difficulties in Mathematizing Word Problems in Algebra. Eurasia Journal of Mathematics, Science \& Technology Education, 12(9), 2481-2502.

[8] Thomas, M. O. J., \& Tall, D. (2013). Algebra, Symbols, and Translation of Meaning, (December).

[9] Lester, F. (1987). Teaching mathematical problem solving Why Is Mathematical Problem Solving Difficult for Students ?, (November). Retrieved fromhttp://ncm.gu.se/pd f/namnaren/3243_88_3.pdf

[10] Roy, G. J. (2014). Developing Prospective Teachers' Understanding of Addition and Subtraction with Whole Numbers. IUMPST: The Journal, 2(March)

[11] Eugenio, Luis, \& Teresa. (2008). Educational Algebra. Springer, US

[12] Sikukumwa. (2017). Types of Strategies used to Solve Algebraic Word Problems By Grade 12 Ordinary Level Mathematics Learners of Kavango East Region of Namibia, (April).

[13] Ganesen, P., Osman, S., Abu, M. S., \& Kumar, J. A. (2020). The Relationship Between Learning Styles and Achievement of Solving Algebraic Problems Among Lower Secondary School Students. International Journal of Advanced Science and Technology, 29(9S), 2563-2574

[14] Brodesky, B. A., Parker, C., Murray, E., \& Katzman, L. (2002). Accessibility Strategies Toolkit for Mathematics. Education Development Center, Inc.

[15] Wu, H. (2009). Learning Algebra. Slightly edited version of a presentation at the University of Oregon, Eugene, OR.

[16] Wu, H. (2016). Teaching School Mathematics: Algebra. American Mathematical Society.

[17] Kaiser, G. (2017). Proceedings of the 13th International Congress on Mathematical Education.

[18] Kieran, C. (1992). The learning and teaching of school algebra. Handbook of Research on Mathematics Teaching and Learning, 390-419.

[19] Sebastian, M., A. (2017). Students’ Gender, Learning Style, and Difficulties in Solving Problems in College Algebra. International Journal of Multidisciplinary Research and Modern Education, 3(2), 87-95

[20] Bull, R., Cleland, A. A., \& Mitchell, T. (2013). Gender differences in the spatial representation of number. Journal of Experimental Psychology: General, 142, 181-192. https://doi.org/10.1037/a0028387.

[21] Rosselli, M., Ardila, A., Matute, E., \& Inozemtseva, O.
(2009). Gender differences and cognitive correlates of mathematical skills in school-aged children. Child Neuropsychology, 15, 216-231. https://doi.org/10.1080/ 09297040802195205.

[22] Hutchison, J., E., Lyons, I., M., \& Ansari, D. (2019). More Similar Than Different: Gender Differences in Children's Basic Numerical Skills Are the Exception Not the Rule. Child Development, 90(1), 66-79.

[23] Lyons, I. M., Price, G. R., Vaessen, A., Blomert, L., \& Ansari, D. (2014). Numerical predictors of arithmetic success in grades 1-6. Developmental Science, 17, 714- 726. https://doi.org/10.1111/desc.12152.

[24] Ameer, I., S., \& Singh, P. (2013). Exploring Grade Levels and Gender Differences in Numeracy Thinking Among Secondary School Students. Procedia - Social and Behavioral Sciences, 90, 187-195.

[25] Creswell, J. W. (University of N.-L. (2014). Research Design Qualitative, Quantitative and Mixed Methods Approaches (4th ed.). California: SAGE Publications Asia-Pacific Pte. Ltd.

[26] Rosli, R , Goldsby, D \& Capraro, M.M., (2013). Assessing Students ' Mathematical Problem-Solving and Problem-Pos ing Skills, Asian Social Science; 9(16), 54-60. https://doi.org/10.5539/ass.v9n16p54.

[27] Tambychik, T., Subahan, T., \& Meerah, M. (2010). Students ' Difficulties in Mathematics Problem-Solving: What do they Say ?, 8(5), 142-151. https://doi.org/10.1016/j.sbspro.2010. 12.020 .

[28] Özsoy, G., \& Kuruyer, H. G. (2015). Evaluation of students' mathematical problem solving skills in relation to their reading levels. International Electronic Journal of Elementary Education, 8(1), 581-600.

[29] Schoenfeld, A. H. (2013). Reflections on Problem Solving Theory and Practice Reflections on Problem Solving Theory and Practice, 10(1).

[30] Erbas, A. (2004). Teachers' knowledge of student thinking and their instructional practices in algebra. Retrieved from http://athenaeum.libs.uga.edu/handle/10724/7771.

[31] Christou, K. (2017). How students interpret literal symbols in algebra: A conceptual change approach, (July).

[32] Egodawatte, G. (2009). Is algebra really difficult for all students? Acta Didactica Napocens, 2(4), 101-106.

[33] Menzel, B., \& Clarke, D. (1998). Teachers interpreting algebra: Teachers' views about the nature of algebra. In C. Kanes, M. Goos, \& E. Warren (Eds.), Teaching mathematics in new times (Proceedings of the 21st annual conference of the Mathematics Education Research Group of Australasia, pp. 365-372). Gold Coast, Australia: MERGA.

[34] Powell, S.R., \& Fuchs, L.S. (2014). Does early algebraic reasoning differ as a function of students' difficulty with calculations versus word problems?. Learning Disabilities Research \& Practice (Wiley-Blackwell), 29(3), 106-116. doi:10.1111/ldrp.12037

[35] Osman, S., S. Mohammad, and M. S. Abu. 2015. "A preliminary study on the integral relationship between critical thinking and mathematical thinking among practicing civil engineers.” AIP Conf. Proc. 1660 (1): 
070030. https://doi.org/10.1063/1.4915748

[36] Gray, E., \& Tall, D. (2017). Success and Failure in Mathematics : The Flexible Meaning of Symbols as Process and Concept, (March).

[37] Tajudin, M. (2016). The Link between Higher Order Thinking Skills, Representation and Concepts in Enhancing TIMSS Tasks, 9(2). https://doi.org/10.12973/iji.2016.9214a.

[38] Stan, A., \& Oprea, C. (2015). Test Anxiety and Achievement Goal Orientations of Students at A Romanian University.
Procedia - Social and Behavioral Sciences, 180, 1673 1679.

[39] Vásquez-Colina, M. D., Gonzalez-DeHass, A., R., \& Furner, J., M. (2014). Achievement Goals, Motivation to Learn, and Mathematics Anxiety among Pre-service Teachers. Journal of Research in Education, 24(1), 38-52.

[40] Galbraith, P.L. (1986). The Use of Mathematical Strategies: Factors and Features Affecting Performance. Educ. Stud. Math., 17, 413-441. 